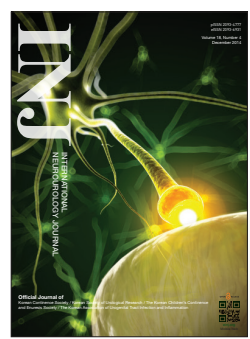

\title{
4-Aminopyridine Improves Lower Urinary Tract Symptoms in a Patient With Benign Prostatic Hyperplasia and Downbeat Nystagmus Syndrome
}

\author{
Michael Strupp ${ }^{1,2}$, Katharina Feil ${ }^{1,2}$, Stanislavs Bardins ${ }^{2}$, Raphaela Waidelich ${ }^{3}$ \\ ${ }^{1}$ Department of Neurology, University Hospital Munich, Campus Grosshadern, Munich, Germany \\ ${ }^{2}$ German Center for Vertigo and Balance Disorders, University Hospital Munich, Campus Grosshadern, Munich, Germany \\ ${ }^{3}$ Department of Urology, University Hospital Munich, Campus Grosshadern, Munich, Germany
}

\begin{abstract}
Aminopyridines are potassium channel blockers that increase the excitability of nerve cells and axons; therefore, they are widely used to treat different neurological disorders. Here we present a patient with idiopathic downbeat nystagmus and lower urinary tract symptoms (LUTS) due to benign prostatic hyperplasia who was treated with the sustained-release form of 4-aminopyridine (4-AP). During treatment with 4-AP, the LUTS improved. This improvement was monitored by using uroflowmetry and the International Prostate Symptom Score. A significant improvement of symptoms was observed in relation to the voided volume. This included an improved emptying of the bladder without an increase in residual urine. In animal studies, both nonselective $\mathrm{K}^{+}$channel blockade and selective voltage-sensitive potassium blockade by 4-AP resulted in increased contraction on rat detrusor strips. To our knowledge, this is the first clinical observation of the mode of action of 4-AP in urological symptoms in humans.
\end{abstract}

Keywords: 4-Aminopyridine; Prostatic Hyperplasia; Lower Urinary Tract Symptoms; Drug Therapy; Neurogenic Urinary Bladder

- Grant Support: This study was supported by the German Ministry of Education and Research (BMBF), Grant No. $01 E O 0901$ to the German Center for Vertigo and Balance Disorders ( $\operatorname{IFB}^{\mathrm{LMU}}$ ).

- Conflict of Interest: M. Strupp is the Joint Chief Editor of the Journal of Neurology, Editor in Chief of Frontiers of Neuro-otology, and Section Editor of F1000. He has received speaker's honoraria from Abbott, UCB, GSK, TEVA, Biogen Idec, Pierre-Fabre, and Hennig Pharma. Except for that, No potential conflict of interest relevant to this article was reported.

Aminopyridines, as potassium channel blockers, have been used to treat different neurological disorders, such as downbeat nystagmus (DBN), episodic ataxia type 2, Lambert-Eaton myasthenic syndrome, gait disorders in multiple sclerosis, and cerebellar gait (EA2) ataxia [1-3]. Their mode of action is an increase in the excitability of nerve cells and axons $[4,5]$.
Here we present a patient, who was treated for idiopathic DBN with the sustained-release form of 4-aminopyridine (4AP or Fampridine), which significantly improved the DBN. The patient was also suffering from lower urinary tract symptoms (LUTS) due to benign prostatic hyperplasia (BPH). During treatment with Fampridine, he realized that urine flow had
Corresponding author: Michael Strupp (iD http://orcid.org/0000-0002-9544-2279 Department of Neurology and German Center for Vertigo and Balance Disorders, University Hospital Munich, Campus Grosshadern, Marchioninistrasse 15, 81377 Munich, Germany

E-mail: michael.strupp@med.uni-muenchen.de

Tel: +49-89-7095-6678 / Fax: +49-89-7095-6673

Submitted: April 11, 2014 / Accepted after revision: June 8, 2014
This is an Open Access article distributed under the terms of the Creative Commons Attribution Non-Commercial License (http://creativecommons.org/licenses/by-nc/3.0/) which permits unrestricted non-commercial use, distribution, and reproduction in any medium, provided the original work is properly cited. 
significantly improved. Having reported this effect several times after periods of starting and stopping the medication, he was carefully examined with and without the presence of 4-AP.

\section{CASE REPORT}

A 71-year-old gastroenterologist presented with vertical oscillopsia and blurred vision. The symptoms had started about one year prior to our examination and were progressive. Neurological examination revealed DBN syndrome. Family history was unremarkable and without evidence of neurodegenerative diseases. Brain magnetic resonance imaging showed minor supratentorial microangiopathic lesions and no cerebellar atrophy or infratentorial lesions. After giving written consent, the patient was treated with Fampridine, the sustained-release form of 4-AP $10 \mathrm{mg}$, orally twice a day. Eye movements were measured with threedimensional videooculography. Before treatment, linear vertical nystagmus with a slow upward phase velocity (SPV \pm standard deviation) during fixation straight ahead of $5.5 \pm 1.0 \mathrm{deg} / \mathrm{sec}$ was documented (Fig. 1A). One hundred and eighty minutes after the first dose of $10 \mathrm{mg}$ of Fampridine the patient had an SPV of $0.5 \pm 1.0 \mathrm{deg} / \mathrm{sec}$. After a treatment period of two weeks with Fampridine $10 \mathrm{mg}$ twice daily SPV was 1.1 \pm $1.0 \mathrm{deg} / \mathrm{sec}$ (Fig. 1B). The patient also subjectively responded very well to this treatment.

The patient had been suffering from LUTS due to BPH (prostate volume, $90 \mathrm{~mL}$ ) for 10 years. He complained of frequency, urgency, nocturia, hesitancy, and poor flow. During treatment with 4-AP, the LUTS improved considerably. The patient reported a much better flow, no frequency or urgency, and a perceptible improvement of nocturia. This subjective improvement was also observed in uroflowmetry. After Fampridine was stopped for a week, the LUTS worsened again. Marked frequency (voiding in the daytime, 7-8 times), nocturia (1-2 times per night), and urgency were reported by the patient. Uroflowmetry (Fig. 1A) showed a low voided volume of only $58 \mathrm{~mL}$, and residual urine was $80 \mathrm{~mL}$. To monitor the LUTS, we used 'The American Urological Association Symptom Index' for benign prostatic hyperplasia (Internatioal Prostate Symptom Score [IPSS]) [6]. The patient's IPSS was 11 (Fig. 2A). On treatment with 4-AP, the LUTS improved considerably. Voiding was reduced to four times during daytime, and nocturia only occurred once or twice a week. Uroflowmetry (Fig. 1B) showed an increased voided volume of $387 \mathrm{~mL}$, and residual urine decreased to $65 \mathrm{~mL}$. After Fampridine was stopped, LUTS reappeared. After two weeks without medication, the patient complained of frequency (voiding during daytime, 8 times) and nocturia (once or twice a night). The IPSS score rose to 15 (Fig. 2B). The patient has now been on medication for two years and still benefits with regard to the DBN and the LUTS. He no longer complains of frequency and nocturia. Voided volume $(552 \mathrm{~mL})$ and residual urine $(80$ $\mathrm{mL}$ ) have remained stable (Fig. 1C). The IPSS has declined to 4 (Fig. 2C). Analysis of the trend of IPSS scores by storage (questionnaire questions 2,4 , and 7) and voiding symptoms (questions $1,3,5$, and 6) shows that the irritative symptom score decreased to $50 \%$ while the voiding symptom score decreased to $25 \%$.

\section{DISCUSSION}

Aminopyridines are nonselective blockers of the Kv family of voltage-gated potassium channels [2]. They act by blocking these channels to improve action potential conduction and neurotransmitter release, for example in exposed demyelinated axons and/or at presynaptic membranes. Animal studies have showed that 4-AP is able to increase excitability of Purkinje cells (PC) and also, in a therapeutic dosage, to restore the diminished precision of pace-making in PC in an animal model of episodic ataxia type 2 (EA2), the tottering mouse $[4,5]$. What are the possible modes of action of 4-AP that could explain the improvement in the contraction of the detrusor muscle described above in this patient with BPH? First, in animal studies the effects of different potassium channel blockers (e.g., 4-AP, glibenclamide, iberiotoxin, charybdotoxin, and apamin) on the urothelium and the detrusor smooth muscle that regulates bladder function, were investigated [7]. Both nonselective $\mathrm{K}^{+}$channel blockade and selective voltage-sensitive potassium blockade by 4-AP resulted in increased contraction on rat detrusor strips [8]. Therefore, a direct effect is possible through a blockade of muscular potassium channels, leading to an increased excitability of the detrusor muscle by which urinary flow rate can increase and residual volume decrease. Second, the detrusor muscle is innervated by autonomic parasympathetic nerves via acetylcholine [9]. Aminopyridines are known to increase the release of different neurotransmitters, including acetylcholine, noradrenaline, dopamine, and serotonin; all closely related to the autonomic nervous system [10]. Furthermore, in animal models, the increasing effect of 4-AP on sympathetic preganglionic neurons was shown to be possibly due to an increase in transmitter release by the presynaptic terminal [11]. It is assumed that amino- 
A Uroflowmetry and videooculography before start of medication

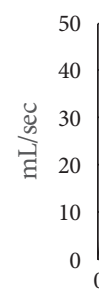

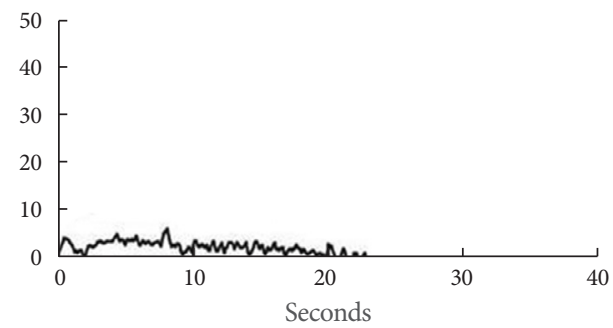

Max. time:

Max. flow rate:

Mean flow rate:

Volume:

Time till max. flow:

F-Index:
$22 \mathrm{sec}$

$6 \mathrm{~mL} / \mathrm{sec}$

$3 \mathrm{~mL} / \mathrm{sec}$

$58 \mathrm{~mL}$

$8 \mathrm{sec}$

1

B

Uroflowmetry and videooculography on medication with Fampridine

Uroflowmetry

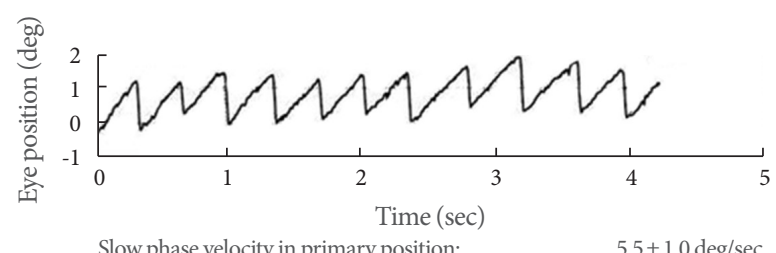

Slow phase velocity in primary position:

$5.5 \pm 1.0 \mathrm{deg} / \mathrm{sec}$

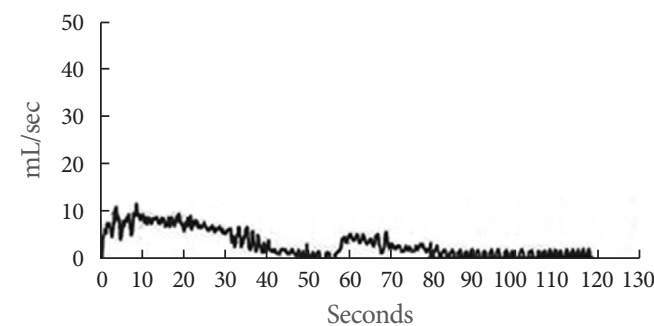

$\begin{array}{ll}\text { Max. time: } & 118 \mathrm{sec} \\ \text { Max. flow rate: } & 12 \mathrm{~mL} / \mathrm{sec} \\ \text { Mean flow rate: } & 3 \mathrm{~mL} / \mathrm{sec} \\ \text { Volume: } & 387 \mathrm{~mL} \\ \text { Time till max. flow: } & 9 \mathrm{sec} \\ \text { F-Index: } & 2\end{array}$

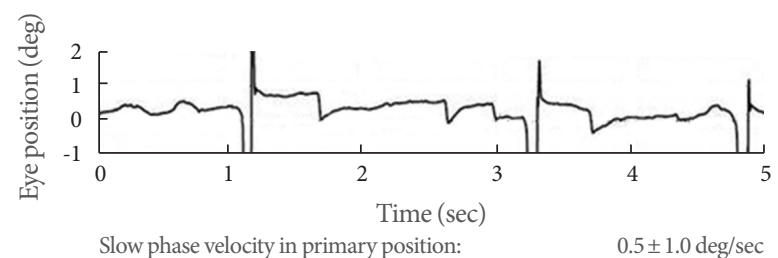

c

Uroflowmetry and videooculography on medication with Fampridine long-term follow-up

Uroflowmetry

Videooculography
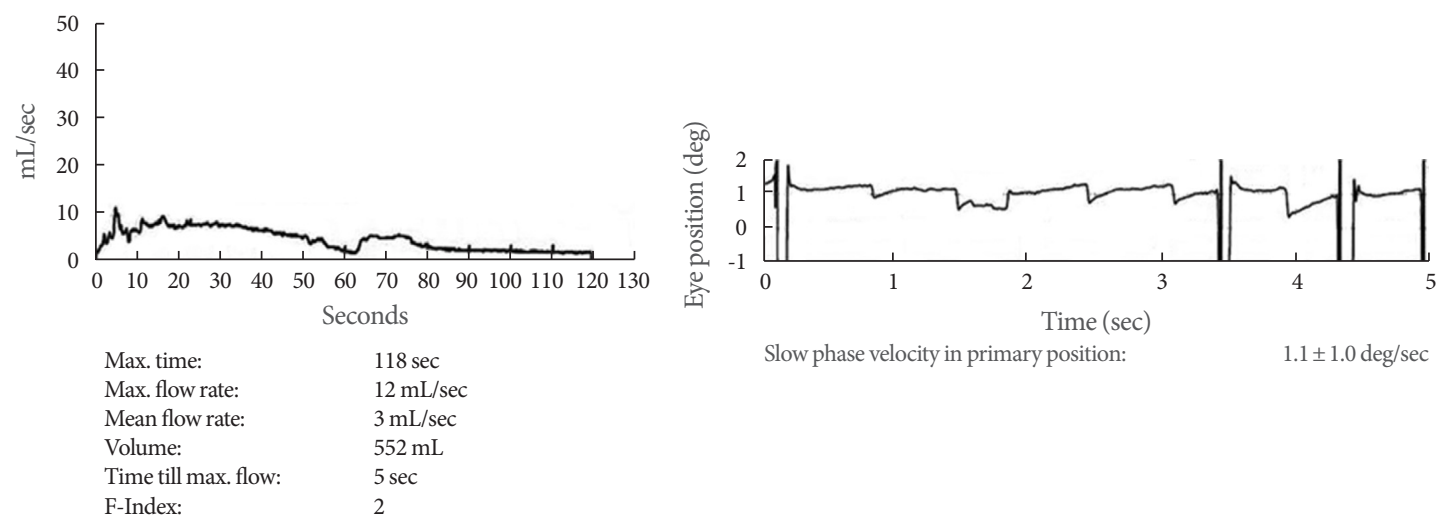

Fig. 1. (A) Uroflowmetry (left) and videooculography (right) in the primary position without medication; (B) uroflowmetry and videooculography after two weeks of treatment with the sustained-release form of 4-aminopyridine (Fampridine); (C) uroflowmetry and videooculography after long-term treatment with Fampridine. Uroflowmetry shows the improved emptying of the bladder and an increase in voided volume. Videooculography comprises original recordings of vertical eye movements of the patient in the primary position. Values given are mean slow upward phase velocity (SPV) in deg/sec. It shows the downbeat nystagmus decreasing in terms of mean SPV. 


\begin{tabular}{|c|c|c|c|c|c|c|}
\hline \multicolumn{7}{|l|}{ International Prostate Symptom Score (IPSS) } \\
\hline 1. Over the past 4 weeks, how often have you had a sensation of not emptying your bladder completely after you finished urinating? & 0 & 1 & (2) & 3 & 4 & 5 \\
\hline 2. Over the past 4 weeks, how often have you had to urinate again less than two hours after you finished urinating? & 0 & (1) & 2 & 3 & 4 & 5 \\
\hline 3. Over the past 4 weeks, how often have you found you stopped and started again several times when you urinated? & (0) & 1 & 2 & 3 & 4 & 5 \\
\hline 4. Over the past 4 weeks, how often have you found it difficult to postpone urination? & 0 & 1 & (2) & 3 & 4 & 5 \\
\hline 5. Over the past 4 weeks, how often has your urinary stream been weaker than usual? & 0 & 1 & 2 & 3 & 4 & (5) \\
\hline \multirow[t]{2}{*}{ 6. Over the past 4 weeks, how often have you had to push or strain to begin urination? } & (0) & 1 & 2 & 3 & 4 & 5 \\
\hline & None & 1 time & 2 times & 3 times & 4 times & $\begin{array}{l}5 \text { or more } \\
\text { times }\end{array}$ \\
\hline $\begin{array}{l}\text { 7. Over the past } 4 \text { weeks, how many times, in general, did you get up to urinate from the time } \\
\text { you went to bed at night until the time you got up in the morning? }\end{array}$ & 0 & (1) & 2 & 3 & 4 & 5 \\
\hline Total IPSS score & \multicolumn{6}{|c|}{11} \\
\hline
\end{tabular}

\begin{tabular}{|c|c|c|c|c|c|c|c|}
\hline \multicolumn{8}{|c|}{ Quality of life due to urinary symptoms } \\
\hline & Delighted & Pleased & $\begin{array}{l}\text { Mostly satis- } \\
\text { fied }\end{array}$ & $\begin{array}{c}\text { Mixed - neither } \\
\text { satisfied nor dissatisfied }\end{array}$ & $\begin{array}{c}\text { Mostly } \\
\text { dissatisfied }\end{array}$ & Unhappy & Terrible \\
\hline $\begin{array}{l}\text { 1. If you were to spend the rest of your life with your urinary condition just the way } \\
\text { it is now, how would you feel about that? }\end{array}$ & 0 & 1 & 2 & (3) & 4 & 5 & 6 \\
\hline
\end{tabular}

1. Over the past 4 weeks, how often have you had a sensation of not emptying your bladder completely after you finished urinating?

2. Over the past 4 weeks, how often have you had to urinate again less than two hours after you finished urinating?

3. Over the past 4 weeks, how often have you found you stopped and started again several times when you urinated?

4. Over the past 4 weeks, how often have you found it difficult to postpone urination?

5. Over the past 4 weeks, how often has your urinary stream been weaker than usual?

6. Over the past 4 weeks, how often have you had to push or strain to begin urination?

7. Over the past 4 weeks, how many times, in general, did you get up to urinate from the time you went to bed at night until the time you got up in the morning?

Total IPSS score

\begin{tabular}{|c|c|c|c|c|c|}
\hline 0 & 1 & (2) & 3 & 4 & 5 \\
\hline 0 & 1 & 2 & (3) & 4 & 5 \\
\hline (1) & 1 & 2 & 3 & 4 & 5 \\
\hline 0 & 1 & 2 & (3) & 4 & 5 \\
\hline 0 & 1 & 2 & 3 & 4 & (5) \\
\hline 0 & (1) & 2 & 3 & 4 & 5 \\
\hline None & 1 time & 2 times & 3 times & 4 times & $\begin{array}{c}5 \text { or more } \\
\text { times }\end{array}$ \\
\hline 0 & (1) & 2 & 3 & 4 & 5 \\
\hline \multicolumn{6}{|c|}{15} \\
\hline
\end{tabular}

\begin{tabular}{|c|c|c|c|c|c|c|c|}
\hline \multicolumn{8}{|c|}{ Quality of life due to urinary symptoms } \\
\hline & Delighted & Pleased & $\begin{array}{l}\text { Mostly satis- } \\
\text { fied }\end{array}$ & $\begin{array}{c}\text { Mixed - neither } \\
\text { satisfied nor dissatisfied }\end{array}$ & $\begin{array}{c}\text { Mostly } \\
\text { dissatisfied }\end{array}$ & Unhappy & Terrible \\
\hline $\begin{array}{l}\text { 1. If you were to spend the rest of your life with your urinary condition just the way } \\
\text { it is now, how would you feel about that? }\end{array}$ & 0 & 1 & 2 & (3) & 4 & 5 & 6 \\
\hline
\end{tabular}

C it is now, how would you feel about that?

\section{International Prostate Symptom Score (IPSS)}

1. Over the past 4 weeks, how often have you had a sensation of not emptying your bladder completely after you finished urinating?

2. Over the past 4 weeks, how often have you had to urinate again less than two hours after you finished urinating?

3. Over the past 4 weeks, how often have you found you stopped and started again several times when you urinated?

4. Over the past 4 weeks, how often have you found it difficult to postpone urination?

5 . Over the past 4 weeks, how often has your urinary stream been weaker than usual?

6. Over the past 4 weeks, how often have you had to push or strain to begin urination?

7. Over the past 4 weeks, how many times, in general, did you get up to urinate from the time you went to bed at night until the time you got up in the morning?

Total IPSS score

$\begin{array}{cccccc}\text { (1) } & 1 & 2 & 3 & 4 & 5 \\ 0 & \text { (1) } & 2 & 3 & 4 & 5 \\ \text { (1) } & 1 & 2 & 3 & 4 & 5 \\ 0 & \text { (1) } & 2 & 3 & 4 & 5 \\ 0 & 1 & \text { (2) } & 3 & 4 & 5 \\ \text { (1) } & 1 & 2 & 3 & 4 & 5 \\ \text { None } & 1 \text { time } & 2 \text { times } & 3 \text { times } & 4 \text { times } & 5 \text { or more } \\ \text { times } \\ \text { (1) } & 1 & 2 & 3 & 4 & 5 \\ & & & & & \end{array}$

\begin{tabular}{|c|c|c|c|c|c|c|c|}
\hline \multicolumn{8}{|c|}{ Quality of life due to urinary symptoms } \\
\hline & Delighted & Pleased & $\begin{array}{l}\text { Mostly satis- } \\
\text { fied }\end{array}$ & $\begin{array}{c}\text { Mixed - neither } \\
\text { satisfied nor dissatisfied }\end{array}$ & $\begin{array}{c}\text { Mostly } \\
\text { dissatisfied }\end{array}$ & Unhappy & Terrible \\
\hline $\begin{array}{l}\text { 1. If you were to spend the rest of your life with your urinary condition just the way } \\
\text { it is now, how would you feel about that? }\end{array}$ & 0 & (1) & 2 & 3 & 4 & 5 & 6 \\
\hline
\end{tabular}

Fig. 2. The American Urological Association Symptom Index for benign prostatic hyperplasia (International Prostate Symptom Score score) of the patient before medication (A), after two weeks without Fampridine treatment (B), and after long-term treatment with Fampridine (C). 
pyridines can increase the excitability of both the sympathetic and the parasympathetic branches of the autonomic nervous systems. Although these mechanisms cannot explain the observed effects on the improvement of storage symptoms (frequency, urgency, and nocturia), they may be indirect effects due to decreased residual urine volume. Therefore, the increased activity of these nerves during voiding can also improve bladder function. It has also been reported that neurogenic bladder secondary to Lambert-Eaton myasthenic syndrome - caused by autoantibodies against the $\mathrm{P} / \mathrm{Q}$-calcium channel and thereby reduced neurotransmission - responds to treatment with 3,4-diaminopyridine [1].

However, this reported effect could only be observed in uroflowmetry because the patient did not agree to more invasive procedures, such as urodynamics. Through uroflowmetry observation we have documented a significant improvement of the symptoms in relation to the voided volume and IPSS score, and at the same time, the patient's residual urine did not increase. In summary, this drug shows a better emptying of the bladder without residual urine, in contrast to other drugs that are usually used in LUTS. Finally, the clinical effect in this patient was convincing and has persisted now for over two years. This effect should be evaluated in more affected subjects. Further, the mode of action should be examined in animal models of BPH.

\section{ACKNOWLEDGEMENTS}

We thank Katie Ogston for copy-editing the manuscript. We thank E. Zemanek, MD from Augsburg for participating in this observation.

\section{REFERENCES}

1. Sanders DB, Massey JM, Sanders LL, Edwards LJ. A randomized trial of 3,4-diaminopyridine in Lambert-Eaton myasthenic syndrome. Neurology 2000;54:603-7.

2. Sedehizadeh S, Keogh M, Maddison P. The use of aminopyridines in neurological disorders. Clin Neuropharmacol 2012;35:191-200.

3. Strupp M, Kalla R, Glasauer S, Wagner J, Hufner K, Jahn K, et al. Aminopyridines for the treatment of cerebellar and ocular motor disorders. Prog Brain Res 2008;171:535-41.

4. Alviña K, Khodakhah K. The therapeutic mode of action of 4-aminopyridine in cerebellar ataxia. J Neurosci 2010;30:7258-68.

5. Etzion Y, Grossman Y. Highly 4-aminopyridine sensitive delayed rectifier current modulates the excitability of guinea pig cerebellar Purkinje cells. Exp Brain Res 2001;139:419-25.

6. Diener HC, Dichgans J, Bacher M, Guschlbauer B. Characteristic alterations of long-loop "reflexes" in patients with Friedreich's disease and late atrophy of the cerebellar anterior lobe. J Neurol Neurosurg Psychiatry 1984;47:679-85.

7. Hidayat Santoso AG, Liang W. Bladder contractility is mediated by different $\mathrm{K}+$ channels in the urothelium and detrusor smooth muscle. J Pharmacol Sci 2011;115:127-34.

8. Ning Lo W, Liang W. Blockade of voltage-sensitive K+ channels increases contractility more in transverse than in longitudinal rat detrusor strips. Urology 2009;73:400-4.

9. Satoh K, Motomura M, Suzu H, Nakao Y, Fujimoto T, Fukuda T, et al. Neurogenic bladder in Lambert-Eaton myasthenic syndrome and its response to 3,4-diaminopyridine. J Neurol Sci 2001;183:1-4.

10. Grijalva I, Guizar-Sahagun G, Rodriguez-Pacheco D, Francisco-Arguelles C, Castaneda-Hernandez G, Palma-Aguirre JA. Gastric emptying effect by 4 -aminopyridine in patients with chronic spinal cord injury. Arch Med Res 2007;38:392-7.

11. Laskey W, Schondorf R, Polosa C. Effects of 4-aminopyridine on sympathetic preganglionic neuron activity. J Auton Nerv Syst 1984; 11:201-6. 